\title{
PREVALENCIA MICROBIANA EM DIVERSAS AMOSTRAS CLÍNICAS OBTIDAS DE PACIENTES DO CTI DE UM HOSPITAL MILITAR
}

\author{
Cecília Santana Bala Pereira \\ Discente do Curso de Farmácia da Universidade Severino Sombra, Vassouras/RJ, \\ me_cissa@hotmail.com \\ Maria Eduarda Goulart \\ Discente do Curso de Farmácia da Universidade Severino Sombra, Vassouras/RJ \\ dudinha17_goulart@hotmail.com
}

Gleiser Tupinambá

Farmacêutica do Setor de Análises Clínicas do Hospital da Força Aérea do Galeão, Rio de Janeiro/RJ, gleiser@gmail.com

\section{Saulo Roni Moraes}

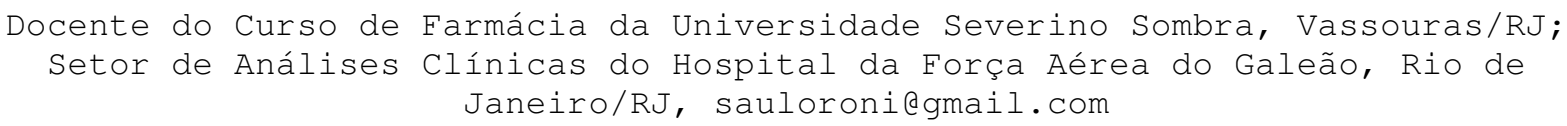

Resumo. Em razão da importância da evolução da resistência microbiana e da urgência de controlar as infecções hospitalares em áreas de grande risco como os Centros de Terapia Intensiva (CTIS), surgiu o interesse em verificar a prevalência microbiana em diversas culturas de amostras clínicas de pacientes internados no Centro de Terapia Intensiva do Hospital da Força Aérea do Galeão - Rio de Janeiro (HFAG), observando também a suscetibilidade dos micro-organismos frente aos antimicrobianos. Foram processados e analisados os resultados de 292 amostras de materiais diversos (urina, ponta de cateter, aspirado endotraqueal e hemocultura) no Laboratório de Análises Clínicas do HFAG/RJ, no período de janeiro a abril de 2012, procedentes de pacientes do CTI, sendo 75 de urina, 37 de ponta de cateter, 87 de aspirado endotraqueal e 93 de hemocultura. Dessas, 139 (47,60\%) foram positivas, sendo: urina (31/75); ponta de cateter (9/37); aspirado endotraqueal (72/87); hemocultura (27/93).

Palavras-Chave: Centro de Terapia Intensiva, resistência aos antibióticos, infecção hospitalar.

\section{Microbial Prevalence in Several Clinical Samples Obtained from the Patients of a Hospital Military ICU}

\begin{abstract}
Given the importance of the development of microbial resistance and the urgency to control hospital infections in high-risk areas such as intensive care centers (ICCs), occurred the interest in ascertaining the prevalence of microbial cultures in several clinical specimens from patients hospitalized in Intensive Care Center of the Air Force Hospital Galeão - Rio de Janeiro (HFAG), noting also the susceptibility of microorganisms against antimicrobial agents used in the ICC of the hospital. Were processed and analyzed the results of 292 samples of several materials (urine, catheter tip, tracheal secretions and blood culture) in Clinical Laboratory HFAG/RJ in the period January-
\end{abstract}

Revista de Saúde, Vassouras, v. 3, n. 2, p. 49-58, jul./dez., 2012 
Prevalência Microbiana em Diversas Amostras Clínicas obtidas de Pacientes do CTI de um Hospital Militar Cecília Santana Bala Pereira, Maria Eduarda Goulart, Gleiser Tupinambá e Saulo Roni Moraes

April 2012, coming from the ICU patients, which 75 urine, 37 catheter tip, 87 tracheal aspirates and 93 blood cultures. Of these, 139 (47.60\%) were positive, as follows: urine (31/75); catheter tip (9/37), tracheal aspirates (72/87), blood culture (27/93).

Keywords: Intensive Care Centre, antibiotic resistances, Hospital infections.

\section{Introdução}

Embora represente menos de $10 \%$ do total de leitos de um hospital, cerca de $25 \%$ das infecções hospitalares ocorrem no CTI, sendo, por isso, o ambiente hospitalar mais propício ao risco de infecções (Pereira et al.; 2000; Diener et al.; 1996; Leiser et al; 2007). Pacientes internados nessas unidades têm de 5-10 vezes mais probabilidade de adquirir infecções (Lima et al.; 2007; Moura et al.; 2007), devido à gravidade das doenças e a exposição aos fatores de risco, bem como procedimentos invasivos com finalidades diagnóstica e terapêutica, e o tempo prolongado de permanência no CTI (Lima et al.; 2007; Moura et al.; 2007; Padrão et al.; 2012; Carvalho e Marques 1999; Leiser et al.; 2007; Boletim Epidemiológico Paulista 2006; Neta et al.; 2008).

As infecções hospitalares representam um grande problema de saúde pública, pois aumentam o tempo de internação, elevam a morbidade e mortalidade dos pacientes, além de aumentarem os custos com o tratamento e terem relação direta com o crescimento de microorganismos multirresistentes (Lisboa, 2007; Filho et al.; 2006; Padrão, 2012). Por isso, é essencial conhecer a microbiota de cada CTI, para que seja possível localizar o foco e determinar o patógeno causador da infecção, tornando mais dirigido e racional o tratamento (Moraes \& Santos, 2003).

É importante mencionar que pacientes infectados por bactérias multirresistentes aos antibióticos apresentam maior taxa de mortalidade do que os pacientes infectados por bactérias sensíveis. Essa mortalidade está mais relacionada com o tratamento impróprio dos pacientes do que com a multirresistência adquirida pelas bactérias (Silva et al.; 2011).

Em razão da importância da evolução da resistência microbiana e da urgência de controlar as infecções hospitalares em áreas de grande risco, como os Centros de Terapia Intensiva (CTIs), surgiu o interesse em verificar a prevalência microbiana em diversas culturas de amostras clínicas obtidas de pacientes internados no Centro de Terapia Intensiva (CTI) do Hospital da Força Aérea do Galeão - Rio de Janeiro (HFAG), observando também a suscetibilidade desses micro-organismos frente aos antimicrobianos utilizados.

\section{Materiais e Métodos}

O estudo define-se como prospectivo e descritivo, para o qual foram processados e analisados os resultados de 292 amostras de materiais diversos (aspirado endotraqueal, hemocultura, urina e ponta de cateter), no laboratório de análises clínicas do HFAG/Rio de Janeiro, no período de janeiro a abril de 2012, procedentes de pacientes do CTI, sendo 93 de hemocultura, 75 de urina, 87 de aspirado endotraqueal, 37 de ponta de cateter. Dessas amostras $139(47,60 \%)$ foram positivas.

\section{Resultados}

Foram processadas 292 amostras. Dessas, 139 (47,60\%) foram positivas, sendo: hemocultura (93/292); urina (75/292); aspirado endotraqueal (87/292); ponta de cateter (37/292).

Das amostras de urina, 31/75 (41,33\%) foram positivas para microorganismos potencialmente patogênicos, dentre os quais se destacou com maior prevalência células leveduriformes com 13,33\%, Klebsiella pneumoniae e Proteus mirabilis, ambas com 6,66\%, e Escherichia coli com 5,33\%. 
Prevalência Microbiana em Diversas Amostras Clínicas obtidas de Pacientes do CTI de um Hospital Militar Cecília Santana Bala Pereira, Maria Eduarda Goulart, Gleiser Tupinambá e Saulo Roni Moraes

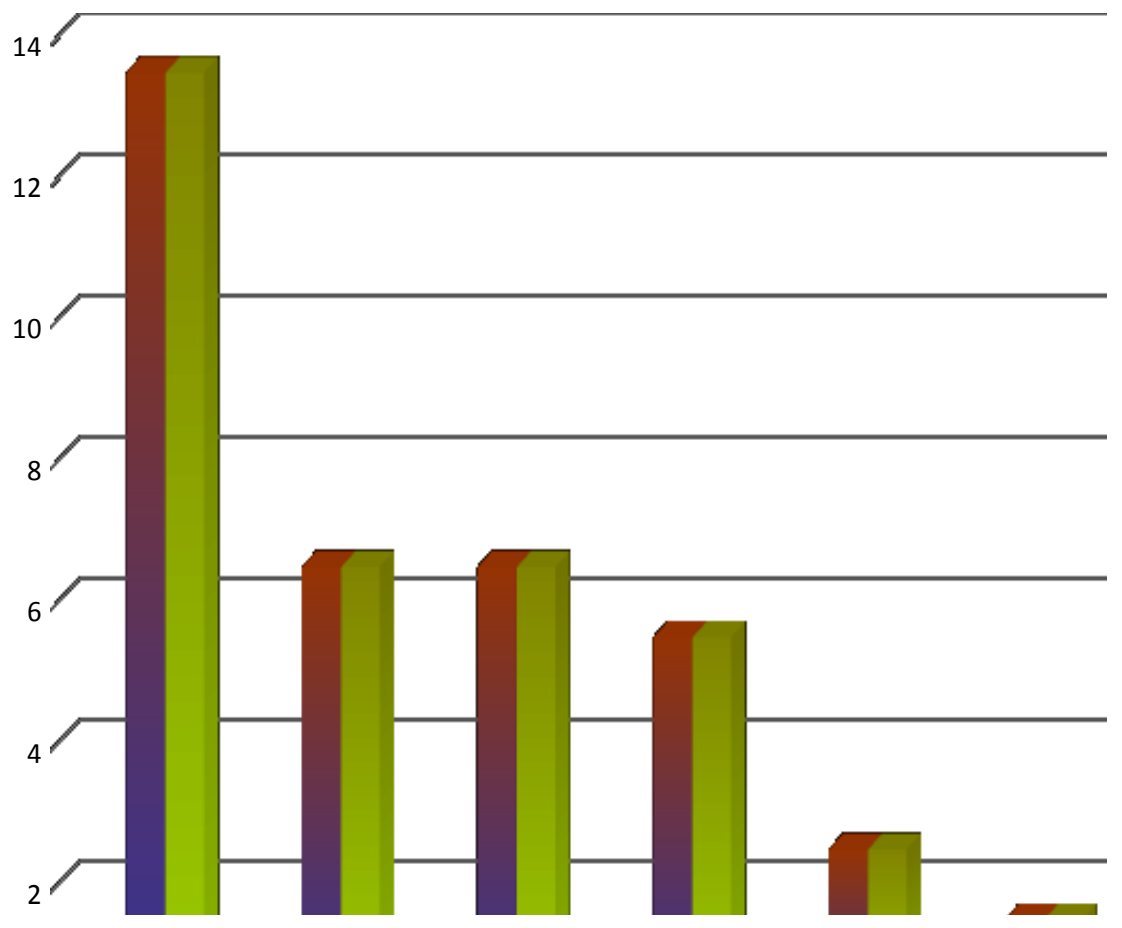

Figura 1. Percentual dos micro-organismos isolados das amostras de urina de pacientes internos no CTI do HFAG, Rio de Janeiro, 2012.

Das 9/37 amostras de cateter positivas (24,32\%), 5,40\% foram para Pseudomonas aeruginosa e para Staphylococcus haemolyticus.

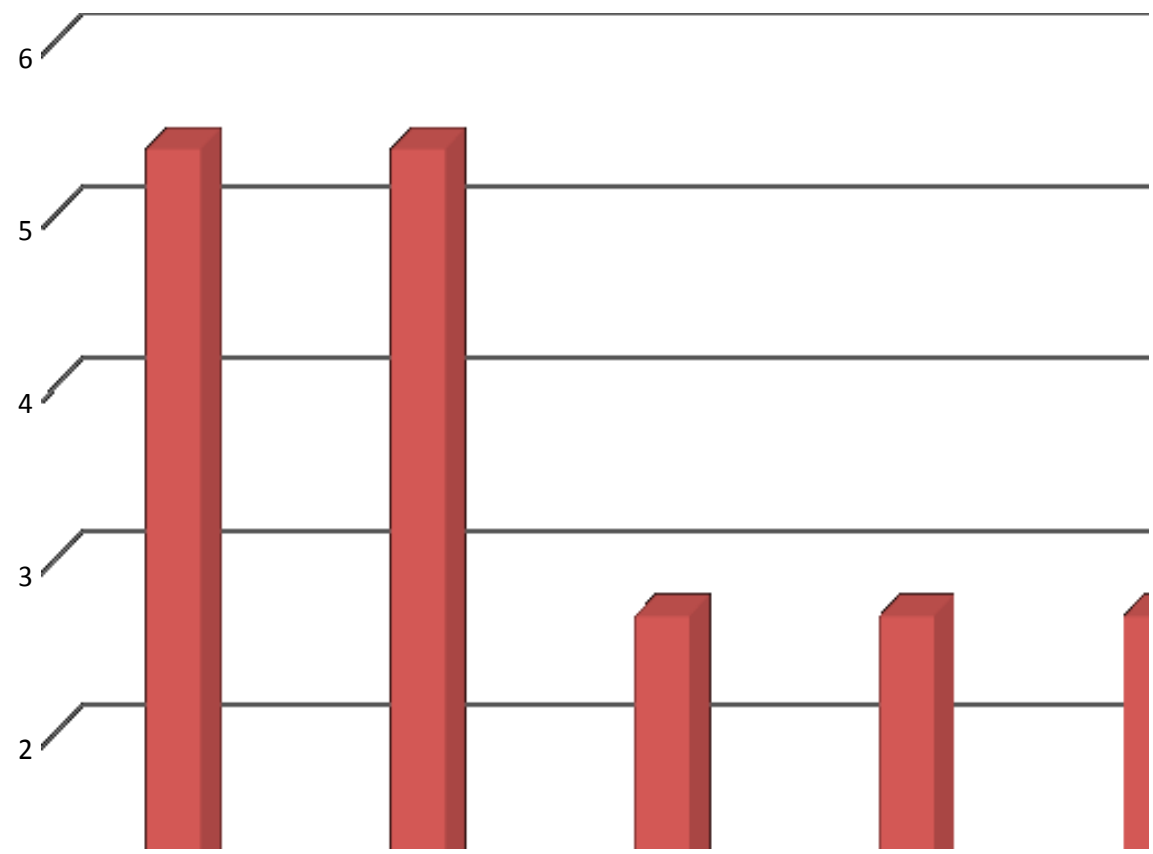

Figura 2. Percentual dos micro-organismos isolados das amostras de ponta de cateter de pacientes internos no CTI do HFAG, Rio de Janeiro, 2012.

Revista de Saúde, Vassouras, v. 3, n. 2, p. 49-58, jul./dez., 2012 
Prevalência Microbiana em Diversas Amostras Clínicas obtidas de Pacientes do CTI de um Hospital Militar Cecília Santana Bala Pereira, Maria Eduarda Goulart, Gleiser Tupinambá e Saulo Roni Moraes

Das 87 amostras de aspirado endotraqueal, $72(82,75 \%)$ foram positivas, destacando Pseudomonas aeruginosa com 16,09\%, células leveduriformes com 14,94\% e Staphylococcus aureus com 9,19\%, Acinetobater baumanin/haemolicus com 5,74\%, Klebsiella pneumoniae com $5,74 \%$ e Proteus mirabilis com 5,74\%.

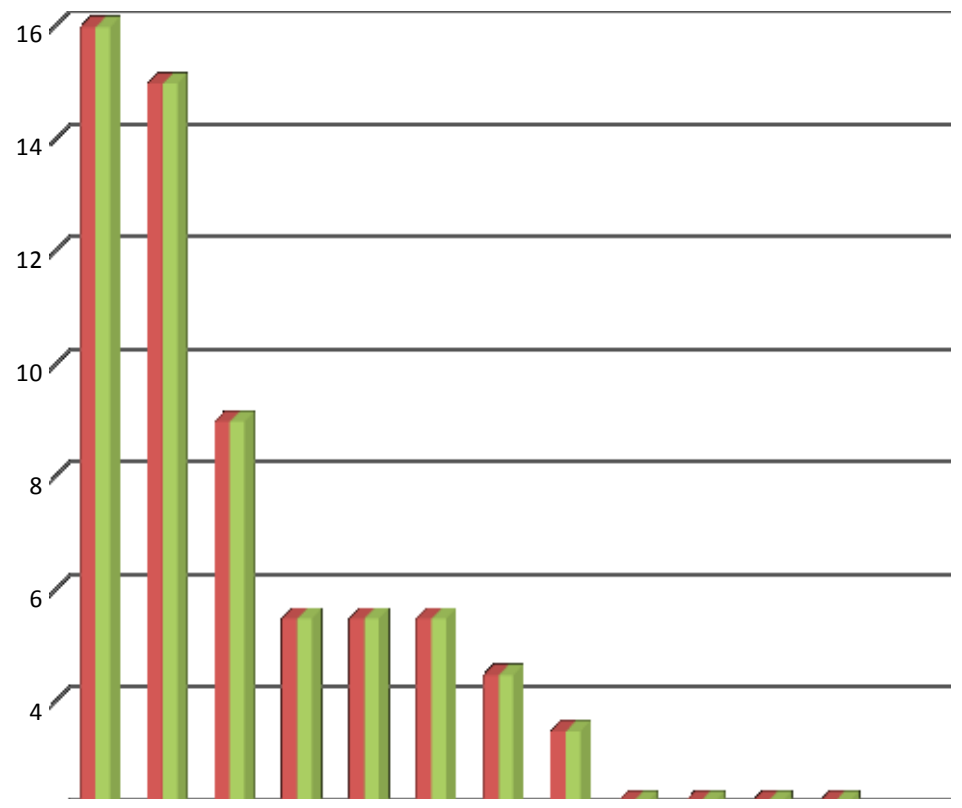

Figura 3. Percentual dos micro-organismos isolados das amostras de aspirado endotraqueal de pacientes internos no CTI do HFAG, Rio de Janeiro, 2012.

Das amostras de hemocultura, 27/93 (29,03\%) foram positivas para Staphylococcus epidermidis com $10,75 \%$ e Proteus mirabilis com $4,30 \%$.

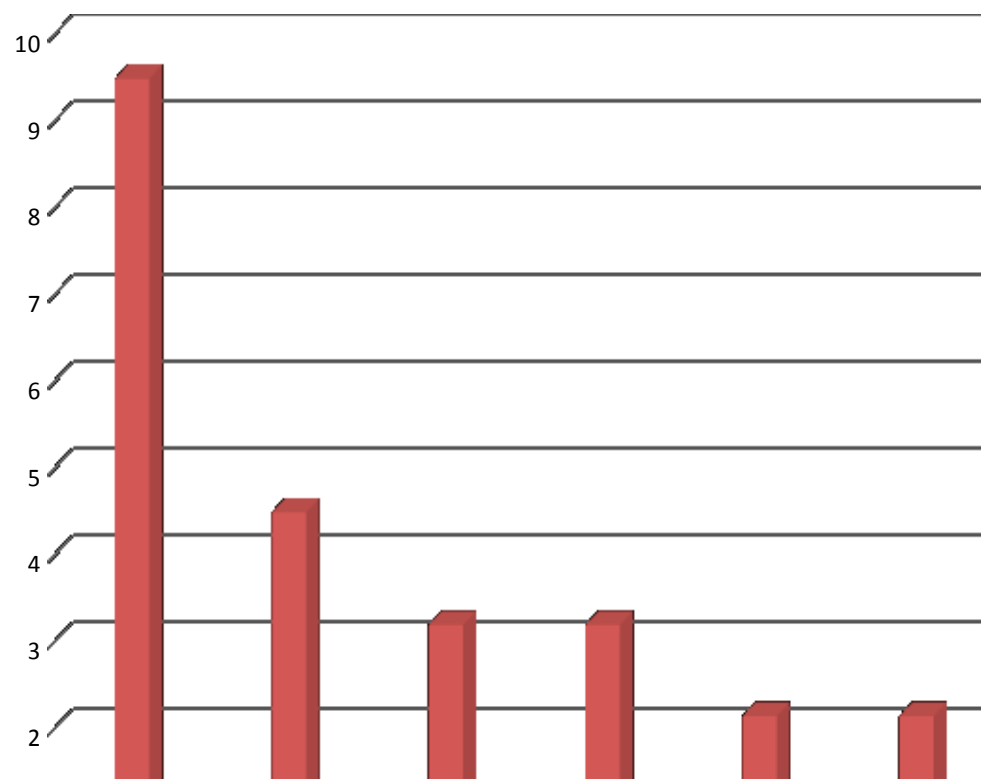

Figura 4. Percentual dos micro-organismos isolados das amostras de hemocultura de pacientes internos no CTI do HFAG, Rio de Janeiro, 2012.

Revista de Saúde, Vassouras, v. 3, n. 2, p. 49-58, jul./dez., 2012 
Na Figura 5 observa-se a prevalência geral dos micro-organismos isolados dos quatro tipos de amostras clínicas (urina, ponta de cateter, aspirado endotraqueal e hemocultura) dos pacientes internados no CTI do HFAG. Nota-se que $16,54 \%$ das amostras positivas revelaram a presença de células leveduriformes, seguidas da Pseudomonas aeruginosa com 12,23\% de prevalência, Proteus mirabilis com 10,79\%, Staphylococcus epidermidis com 8,63\%, Klebsiella pneumoniae com 7,91\%, Staphylococcus aureus com 6,47\%, Escherichia coli com 5,03\%, Acinetobacter baumannii/haemolyticus com 5,03\%, Staphylococcus haemolyticus com 4,31\% e Enterococcus faecalis com $2,87 \%$ de prevalência geral.

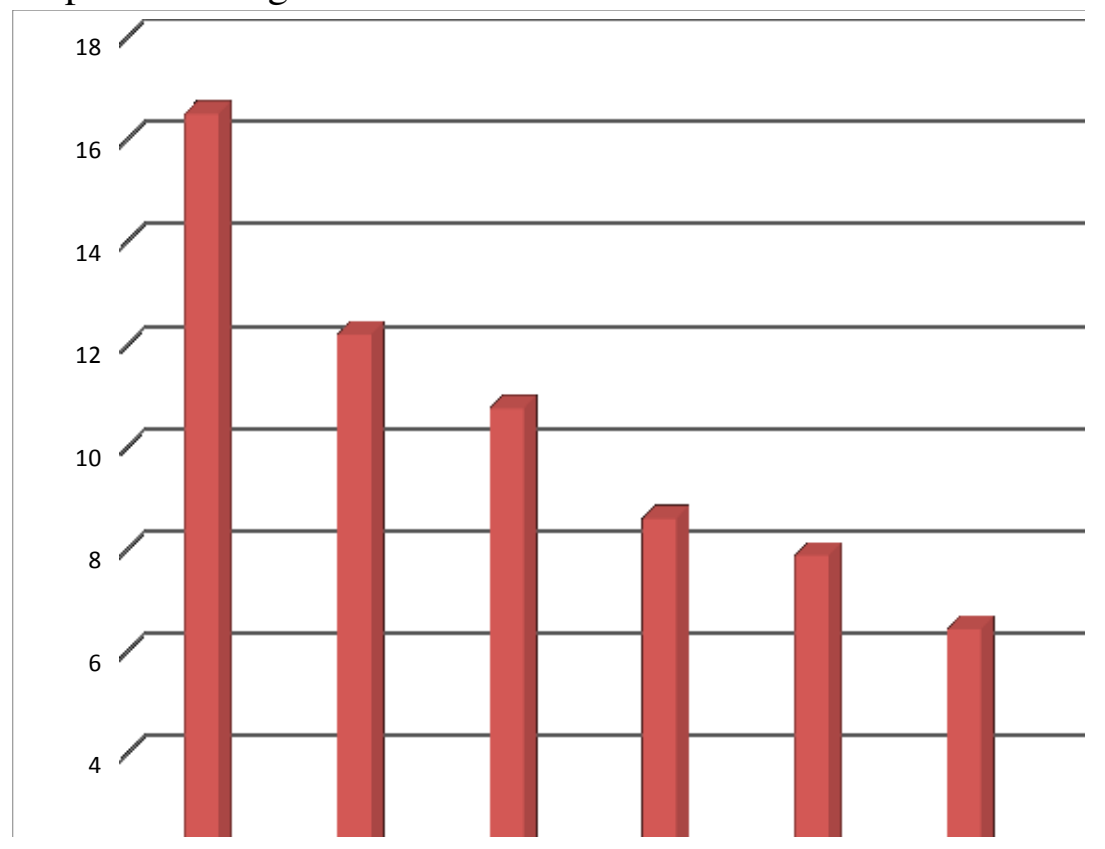

Figura 5. Percentual dos micro-organismos isolados das diversas amostras de pacientes internos no CTI do HFAG, Rio de Janeiro, 2012.

Em relação ao perfil de suscetibilidade dos bacilos não fermentadores, a Pseudomonas aeruginosa isolada de amostras de aspirado endotraqueal, ponta de cateter e urina apresentou $64,70 \%$ de resistência ao meropenem, $58,82 \%$ ao imipenem, $41,17 \%$ de resistência ao cefepime, $29,41 \%$ ao ceftazidima e $23,52 \%$ de resistência a piperacilina/tazobactan; a Acinetobacter baumannii/haemolyticus mostrou $87,5 \%$ de resistência ao meropenem.

Entre as enterobactérias, a Klebsiella pneumoniae isolada das amostras de aspirado endotraqueal, urina e hemocultura apresentou resistência de $66,66 \%$ a ciprofloxacino, $50 \%$ ao cefepime e 16,66\% ao imipenem e também ao meropenem; o Proteus mirabilis isolado dos quatro tipos de amostras mostrou 66,66\% de resistência a ciprofloxacino; da Escherichia coli isolada das amostras de urina e hemocultura, 14,28\% mostrou-se resistente a ciprofloxacino, e $100 \%$ mostrouse sensível ao cefepime, imipenem e meropenem.

Dentre os cocos Gram-positivos, o Staphylococcus aureus isolado de amostras de aspirado endotraqueal e ponta de cateter apresentou $100 \%$ de sensibilidade à vancomicina e 43,3\% de sensibilidade a oxacilina.

Pode-se destacar na Figura 6 que em relação aos bacilos não fermentadores, o Acinetobacter baumannii-haemolyticus isolados de amostras de urina, aspirado endotraqueal e hemocultura só apresentou sensibilidade ao meropenem de $12,50 \%$, a Pseudomonas aeruginosa obtidas de amostras clínicas de urina, ponta de cateter e aspirado endotraqueal mostrou sensibilidade ao meropenem de $35,30 \%$, ao imipenem de $41,18 \%$. 
Nas Figuras 6, 7 e 8 mostram os percentuais de suscetibilidade dos micro-organismos isolados das amostras clínicas: urina, ponta de cateter, aspirado endotraqueal e hemocultura dos pacientes internos do CTI do HFAG.

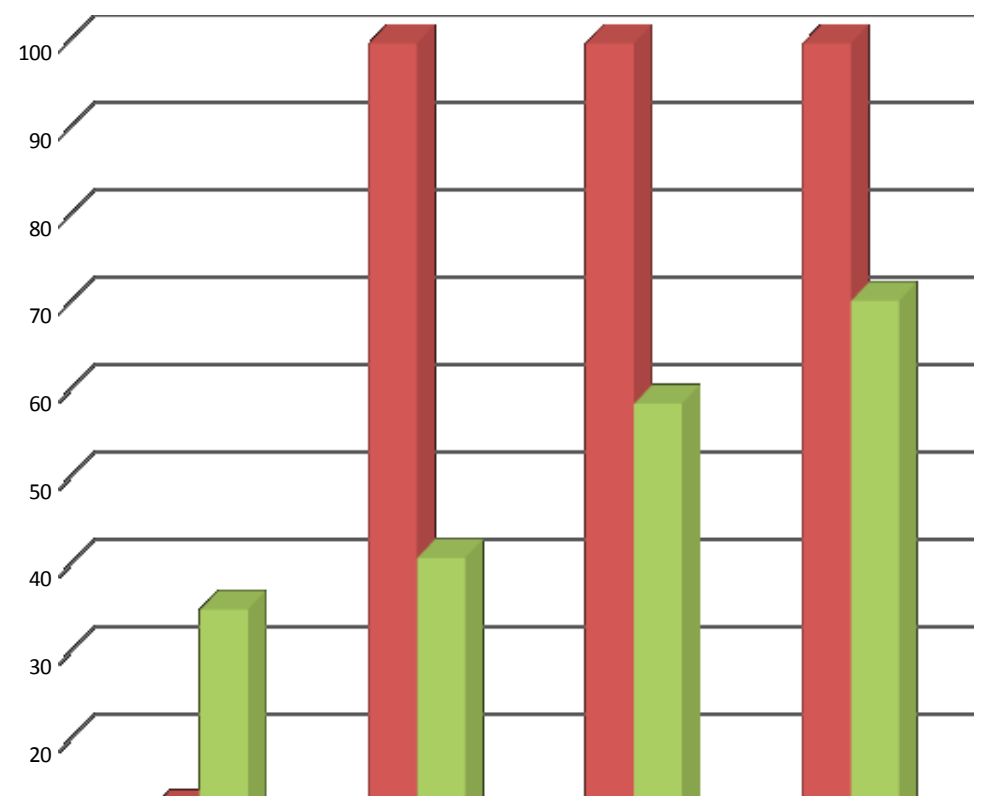

Figura 6. Perfil de sensibilidade antimicrobiana dos micro-organismos não fermentadores isolados de pacientes internos na CTI do HFAG, Rio de Janeiro, 2012.

Na Figura 7 observa-se que entre as enterobactérias, a Klebsiella pneumoniae e o Proteus mirabilis isolados apresentaram resistência a ciprofloxacina, ambos de 66,66\%. A Klebsiella pneumoniae também apresentou sensibilidade de 50\% ao cefepime. A Escherichia coli isolada de amostras de urina e hemocultura apresentou $100 \%$ de sensibilidade ao cefepime, imipenem e meropenem, e $85,72 \%$ a ciprofloxacina.

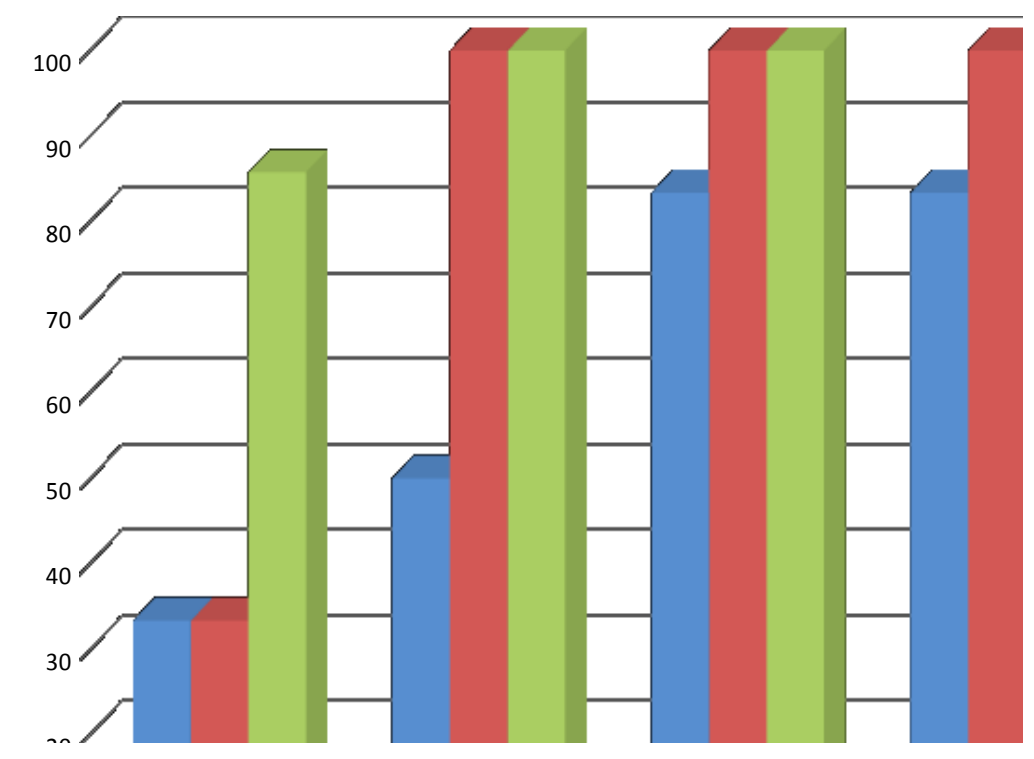

Figura 7. Perfil de sensibilidade antimicrobiana das enterobactérias isoladas de pacientes internos na CTI do HFAG, Rio de Janeiro, 2012.

Revista de Saúde, Vassouras, v. 3, n. 2, p. 49-58, jul./dez., 2012 


\section{Staphylococcus aureus}
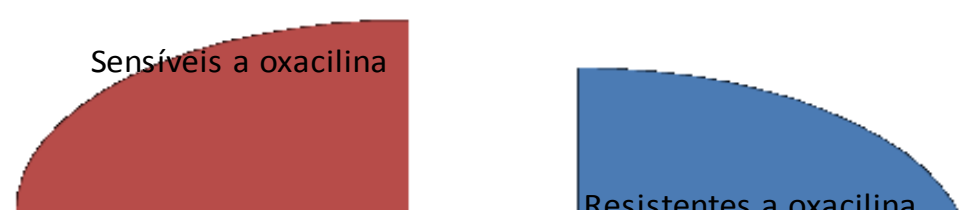

Figura 8. Perfil de resistência antimicrobiana dos cocos Gram-positivos isoladas de pacientes internos na CTI do HFAG, Rio de Janeiro, 2012.

Entre os cocos Gram-positivos, o Staphylococcus aureus mostrou resistência de 66,66\% a oxacilina.

\section{Discussão}

A prevenção das infecções é extremamente importante, já que estas são as maiores causas de morte em CTIs, exigindo grande conhecimento das taxas de infecção, tipo e natureza da infecção, ambiente de aquisição (comunitária, hospitalar, CTI) e perfil dos microorganismos causadores. O conhecimento dos fatores de risco para o desenvolvimento de infecção e sua relação com a mortalidade é essencial, principalmente quando se trata de infecção adquirida no CTI (Lisboa et al, 2007). Este estudo pode servir como base para um estudo maior nacional e ainda ajudar a definir estratégias para diminuir as taxas de infecção no CTI do HFAG, já que se trata de um Hospital de Quarto Escalão, sendo referência para a Força Aérea Brasileira.

Vale ressaltar que os pacientes do HFAG vêm encaminhados de todas as regiões do País para tratamento especializado e, em muitos casos, necessitam de internação no CTI devido à complexidade da patologia. Tais pacientes, geralmente, fizeram uso de antibióticos no início do tratamento, às vezes com insucesso terapêutico, ou seja, previamente expostos a uma antibioticoterapia diferente a utilizada no HFAG. Além disso, o quadro clínico do paciente de CTI requer o uso de ventilação mecânica, sondas urinárias e acessos intravenosos que favorecem a colonização e a infecção destes sítios.

Diversos artigos relatam que Pseudomonas aeruginosa é o patógeno mais frequentemente isolado de pacientes infectados no CTI, seguida por Staphylococcus aureus, estafilococos coagulase negativa, Enterococcus sp, Enterobacter sp, e Candida sp (Wey, Lomar \& Coscina, 1999; Moraes \& Santos, 2003). Em nosso estudo, a Pseudomonas aeruginosa foi isolada em 12,23\% das culturas que apresentaram crescimento bacteriano, seguida do Proteus mirabilis (10,79\%), Staphylococcus epidermidis (8,63\%), Klebsiella pneumoniae (7,91\%) e Staphylococcus aureus, $(6,47 \%)$.

A Pseudomonas aeruginosa é um patógeno oportunista que pode infectar qualquer região do corpo em um paciente suscetível, principalmente em pacientes de Centro de Terapia Intensiva, já que se trata de uma bactéria que pode disseminar facilmente em ambientes hospitalares, além de ser resistente a desinfetantes químicos e diversos antissépticos (Pires et al, 2009). No presente estudo

Revista de Saúde, Vassouras, v. 3, n. 2, p. 49-58, jul./dez., 2012 
foi detectada a presença de Pseudomonas aeruginosa em amostras de aspirado endotraqueal $(16,09 \%)$, ponta de cateter $(5,40 \%)$ e urina $(1,33 \%)$. Os resultados encontrados coincidem com os dados do estudo realizado por Pires e colaboradores, 2009, que observou que a aspirado endotraqueal é a amostra com maior positividade (33\%) para Pseudomonas aeruginosa, seguida das amostras de ponta de cateter com $8 \%$. Um patógeno que se destacou em nosso estudo foi o Proteus mirabilis $(10,79 \%)$. Estudos não têm relatado este patógeno com um agente infeccioso frequente nas infecções de pacientes de CTI. Uma explicação para este ocorrido no HFAG, talvez seja o uso frequente de tigeciclina, um antibiótico de amplo espectro, mas para o qual $P$. mirabilis é naturalmente resistente.

Importante comentar a grande prevalência de Candida sp nessa pesquisa, que apresentou a maior prevalência $(16,54 \%)$ em relação aos demais micro-organismos isolados nas amostras positivas, corroborando dados da literatura que informam uma frequência de aproximadamente $27 \%$ nas amostras de pacientes de CTI. O aumento do isolamento de fungos em pacientes de CTI, em particular Candida sp está relacionado com a utilização de antibióticos de amplo espectro, cateter venoso central, nutrição parenteral, hemodiálise e a administração de corticosteróides (Moraes \& Santos, 2003).

Com relação às hemoculturas, foi possível verificar uma grande variabilidade de bactérias, e também se observou que mais da metade das amostras não apresentaram crescimento bacteriano. Nas amostras positivas (29,03\%), observou-se maior presença de Staphylococcus epidermidis, coincidindo com os dados do estudo de Fernandes e colaboradores, 2011. Acredita-se que o Staphylococcus epidermidis, por fazer parte da microbiota da pele, contaminam o sangue durante a coleta da amostra (Fernandes et al, 2011). Assim, é importante uma educação continuada para orientação da equipe de coleta de sangue sobre os cuidados a serem tomados durante a coleta. Novamente, o Proteus mirabilis se destaca por ser o patógeno mais frequentemente isolado em amostras de hemocultura nos nossos resultados, diferente do estudo de Fernandes et al. em que o Proteus mirabilis apresentou baixa prevalência (1,02\%). É importante mencionar que os resultados de hemocultura, na maioria dos casos, devem ser relacionados com resultados de outras amostras clínicas como aspirado endotraqueal (pneumonia), urina (infecção urinária) e ponta de cateter para melhor compreensão do quadro de bacteremia ou septicemia.

As bactérias mais comuns em pneumonias associadas à ventilação mecânica (PAVM) são bacilos gram-negativos não fermentadores, enterobactérias e Staphylococcus aureus. Na maioria das pesquisas relacionadas à PAVM, a definição da etiologia ocorre após análise microbiológica de lavado broncoalveoar ou aspirado endotraqueal. Nesse estudo, utilizou-se o aspirado endotraqueal para isolar agentes relacionados à infecção pulmonar, por se tratar de ambiente onde há maior quantidade de pacientes intubados e traqueostomizados. As culturas de aspirado endotraqueal revelaram 16,09\% de prevalência de Pseudomonas aeruginosa. Portanto, a condição do paciente internado, sob ventilação mecânica, deve ser considerada como um fator de predisposição para a infecção pela Pseudomonas aeruginosa em vias aéreas, da mesma forma que a adaptabilidade deste microrganismo à infecção destas vias não deve ser negligenciada, ou seja, a alta prevalência deste microrganismo no trato respiratório, não deve ser explicada unicamente pela deficiência imunológica do paciente internado, mas também pela facilidade de infecção ligada ao microrganismo (Pires et al, 2009).

As culturas positivas de ponta de cateter, de acordo com Menezes e colaboradores (2004), apresentaram maior prevalência de Pseudomonas aeruginosa e Staphylococcus coagulase negativa, o que está de acordo com dados apresentados neste trabalho.

Em relação ao percentual de suscetibilidade das cepas bacterianas isoladas, observamos que a Pseudomonas aeruginosa isolada apresentou 64,7\% de resistência para meropenem, 58,82\% para imipenem, $41,17 \%$ para cefepime, $29,41 \%$ para ceftazidima e $23,52 \%$ para piperacilina/tazobactan.

Revista de Saúde, Vassouras, v. 3, n. 2, p. 49-58, jul./dez., 2012 
Pires e colaboradores, 2009, demonstraram mínima resistência ao meropenem e imipenem, porém confirmou a suscetibilidade da Pseudomonas aeruginosa em relação ao cefepime.

Os resultados dos testes de susceptibilidade aos antimicrobianos das amostras de $A$. baumannii mostraram resistência de $87,5 \%$ para meropenem e $100 \%$ de sensibilidade imipenem, cefepime, ceftazidima e piperacilina/tazobactan. No estudo realizado por Leiser, Tognim \& Bedendo (2007), A. baumannii apresentou $100 \%$ de resistência para cefepime, 85,5\% para ceftazidima, 53,5\% para imipenem e 7\% para meropenem.

Em relação aos cocos Gram-positivos, nenhum apresentou resistência à vancomicina e 67\% dos Staphylococcus aureus isolados foram resistentes à oxacilina (MRSA). Num estudo de vigilância efetuado nos hospitais brasileiros esse número ficou na faixa geral de 34\% (Filho, Reschke \& Hörner, 2006).

A resistência antimicrobiana é uma ameaça à saúde pública mundial, estando associada a uma elevada morbimortalidade (Silva et al, 2011). Por isso, além de considerar fatores dependentes do próprio hospedeiro, tais como idade, doença de base e processo mórbido motivador da internação no CTI, é imprescindível conhecer o perfil patogênico dos micro-organismos locais, para que haja um planejamento terapêutico dos pacientes admitidos no CTI, visto que a antibioticoterapia empírica necessita destes dados para um maior sucesso terapêutico (Moraes \& Santos, 2003).

\section{Referências}

Boletim Epidemiológico Paulista (2006). Análise temporal de taxas de infecção hospitalar em Unidades de Terapia Intensiva - utilidade dos diagramas de controle. 3(28): 2006.

Burton, G. R. W., Engelkirk, P. G., (1998). Impacto dos programas de antibióticos sobre os custos e a resistência microbiana. In: Microbiologia para as ciências da saúde. 5 ed. Rio de Janeiro: Guanabara koogan. 5: 101-121.

Carvalho, E. S., Marques, S. R., (1999). Infecção hospitalar em pediatria. Jornal de Pediatria. 75(1): s31-s45.

Ciamponel et al. (2006). Necessidades de cuidados de enfermagem e intervenções terapêuticas em Unidade de Terapia Intensiva: estudo comparativo entre pacientes idosos e não idosos. Acta Paulista de Enfermagem. 19(1): 28-35.

Diener, J. R. C., Coutinho, M. S. S. A., Zoccoli, C. M., (1996). Infecções relacionadas ao cateter venoso central em terapia intensiva. Revista da Associação Médica Brasileira. 42(4): 205214.

Fernandes et al. (2011). Incidência Bacteriana em Hemoculturas no Hospital das Clínicas Samuel Libânio de Pouso Alegre MG. Revista Eletrônica Acervo Saúde. 2: 122-133.

Filho, V. C. B., Reschke, C. R., Hörner, R., (2006). Perfil epidemiológico das infecções hospitalares na Unidade de terapia Intensiva Infantil do Hospital de Caridade e Beneficência de Cachoeira do Sul, RS, Brasil. Revista Brasileira de Análises Clínicas. 38(4): 267-270.

Leiser, J. J., Tognim, M. C. B., Bedendo, J., (2007). Infecções hospitalares em um Centro de Terapia Intensiva de um Hospital de Ensino no Norte do Paraná. Ciência, cuidado e saúde. 6(2): 181-186.

Leite, M.A., Vila, V. S. C., (2005). Dificuldades vivenciadas pela equipe multiprofissional na unidade de terapia intensiva. Revista Latino-Americana de Enfermagem. 13(2): 145-150.

Lima, M. E., Andrade, D., Haas, V. J., (2007). Avaliação Prospectiva da Ocorrência de Infecção em Pacientes Críticos de Unidade de Terapia Intensiva. Revista Brasileira de Terapia Intensiva. 19(3): 342-347.

Revista de Saúde, Vassouras, v. 3, n. 2, p. 49-58, jul./dez., 2012 
Lisboa et al. (2007). Prevalência de Infecção Nosocomial em Unidades de Terapia Intensiva do Rio Grande do Sul. Revista Brasileira de Terapia Intensiva. 19(4): 414-420.

Moraes, A. A. P., Santos, R. L. D., (2003). Infecções em UTI Geral de um Hospital Universitário. Revista Brasileira de Terapia Intensiva. 15(4): 135-141.

Moura et al (2007). Infecção hospitalar: estudo de prevalência em um hospital público de ensino. Revista Brasileira de Enfermagem. 60(4): 416-421.

Neta, C. B. C. S., Costa, T. S., Caldas, A. J. M., (2008). Prevalência de infecções respiratórias na unidade de terapia intensiva de um hospital da rede privada do município de São Luís, MA. Revista do Hospital Universitário/UFMA. 9(2): 42-46.

Padrão et al. (2012). Prevalência de infecções hospitalares em unidade de terapia intensiva. Revista da Sociedade Brasileira de Clínica Médica. 8(2): 125-128.

Pereira et al. (2000). Controle de Infecção Hospitalar em Unidade de terapia Intensiva: desafios e perspectiva. Revista Eletrônica de Enfermagem. 2(1).

Pires et al (2009). Análise epidemiológica de isolados clínicos de Pseudomonas aeruginosa provenientes de hospital universitário. Revista Brasileira de Terapia Intensiva. 21(4): 384-390.

Silva et al. (2011). Prevalência microbiana em culturas diversas de amostras clínicas obtidas de pacientes internos na Unidade de Terapia Intensiva (UTI) do Hospital de Urgência e Emergência de Rio Branco (HUERB) - Acre. Revista Panamericana de Infectologia. 13(3): 26-31.

Wey S. B., Lomar A. V., Coscina A. L (1999). Infecções em UTI. In: Knobel E. eds. Condutas no Paciente Grave. 2 ed. São Paulo: Atheneu. (2): 757-764. 